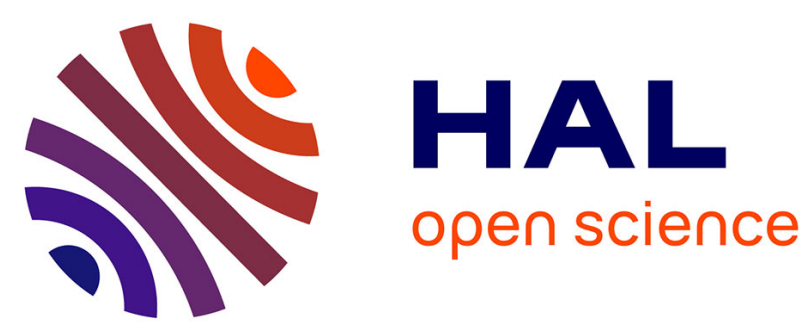

\title{
Geographical isolation caused the diversification of the Mediterranean thorny cushion-like Astragalus L. sect. Tragacantha DC. (Fabaceae)
}

\author{
Laurent Hardion, Pierre-Jean Dumas, Farah Abdel-Samad, Magda Bou
}

Dagher Kharrat, Bostjan Surina, Laurence Affre, Frédéric Médail, Gianluigi

Bacchetta, Alex Baumel

\section{To cite this version:}

Laurent Hardion, Pierre-Jean Dumas, Farah Abdel-Samad, Magda Bou Dagher Kharrat, Bostjan Surina, et al.. Geographical isolation caused the diversification of the Mediterranean thorny cushionlike Astragalus L. sect. Tragacantha DC. (Fabaceae). Molecular Phylogenetics and Evolution, 2016, 97, pp.187-195. 10.1016/j.ympev.2016.01.006 . hal-01444679

\author{
HAL Id: hal-01444679 \\ https://hal.science/hal-01444679
}

Submitted on 24 Feb 2022

HAL is a multi-disciplinary open access archive for the deposit and dissemination of scientific research documents, whether they are published or not. The documents may come from teaching and research institutions in France or abroad, or from public or private research centers.
L'archive ouverte pluridisciplinaire HAL, est destinée au dépôt et à la diffusion de documents scientifiques de niveau recherche, publiés ou non, émanant des établissements d'enseignement et de recherche français ou étrangers, des laboratoires publics ou privés. 


\title{
Geographical isolation caused the diversification of the Mediterranean thorny cushion-like Astragalus L. sect. Tragacantha DC. (Fabaceae)
}

\author{
Laurent Hardion $^{\mathrm{a}, \mathrm{b}, *}$, Pierre-Jean Dumas ${ }^{\mathrm{a}}$, Farah Abdel-Samad ${ }^{\mathrm{a}, \mathrm{c}}$, Magda Bou Dagher Kharrat ${ }^{\mathrm{c}}$, \\ Bostjan Surina $^{\mathrm{d}, \mathrm{e}}$, Laurence Affre ${ }^{\mathrm{a}}$, Frédéric Médail ${ }^{\mathrm{a}}$, Gianluigi Bacchetta ${ }^{\mathrm{f}}$, Alex Baumel ${ }^{\mathrm{a}}$ \\ a Institut Méditerranéen de Biodiversité et d'Ecologie marine et continentale (IMBE), Aix Marseille Université, CNRS, IRD, Avignon Université, Marseille, France \\ ${ }^{\mathrm{b}}$ Laboratoire Image Ville Environnement (LIVE), Université de Strasbourg, CNRS, Strasbourg, France \\ ' Laboratoire Caractérisation Génomique des Plantes, Faculté des Sciences, Université Saint-Joseph, Mar Roukoz, Mkalles, Lebanon \\ ${ }^{\mathrm{d}}$ Natural History Museum Rijeka, Lorenzov prolaz 1, 51000 Rijeka, Croatia \\ e University of Primorska, Faculty of Mathematics, Natural Sciences and Information Technologies, Glagoljaška 8, SI-6000 Koper, Slovenia \\ ${ }^{\mathrm{f}}$ Centro Conservazione Biodiversità, Dipartimento di Scienze della Vita e dell'Ambiente, Università degli Studi di Cagliari, Cagliari, Italy
}

\section{A R T I C L E I N F O}

Article history:

Received 7 June 2015

Revised 5 January 2016

Accepted 11 January 2016

Available online 22 January 2016

Keywords:

Phylogeography

Biogeography

Plant

Biodiversity

Speciation

Vicariance

\begin{abstract}
A B S T R A C T
Understanding the origin and evolution of Mediterranean vascular flora within the long-term context of climate change requires a continuous study of historical biogeography supported by molecular phylogenetic approaches. Here we provide new insights into the fascinating but often overlooked diversification of Mediterranean xerophytic plants. Growing in some of the most stressing Mediterranean environments, i.e. coastal and mountainous opened habitats, the circum-Mediterranean Astragalus L. sect. Tragacantha DC. (Fabaceae) gathers several thorny cushion-like taxa. These have been the subjects of recent taxonomical studies, but they have not yet been investigated within a comprehensive molecular framework. Bayesian phylogenetics applied to rDNA ITS sequences reveal that the diversification of $A$. sect. Tragacantha has roots dating back to the Pliocene, and the same data also indicate an eastern-western split giving rise to the five main lineages that exist today. In addition, AFLP fingerprinting supports an old east-west pattern of vicariance that completely rules out the possibility of a recent eastern origin for western taxa. The observed network of genetic relationships implies that contrary to what is widely claimed in the taxonomic literature, it is range fragmentation, as opposed to a coastal-to-mountain ecological shift, that is likely the main driver of diversification.
\end{abstract}

\section{Introduction}

The composition of a regional flora is the complex result of in situ evolution determined by past environmental changes, as well as dispersal from neighboring or more distant areas. In the Mediterranean Basin, the state of current knowledge is still far from a comprehensive understanding of the drivers of diversification and persistence of a rich flora containing c. 25000 taxa of which half are endemic, some common patterns are emerging (Nieto-Feliner, 2014): recent Mediterranean phylogeographies of widespread taxa have often highlighted an east-west vicariance due to past divergences, some of which occurred earlier than the Pliocene, along with the distinct possibility of repeated migrations

\footnotetext{
This paper was edited by the Associate Editor Stefanie M. Ickert-Bond.

* Corresponding author at: LIVE, Université de Strasbourg, Institut de Botanique, 28 rue Goethe, 67083 Strasbourg Cedex, France.

E-mail address: hardion@unistra.fr (L. Hardion).
}

that could have led to secondary contacts between previously isolated lineages (Mansion et al., 2008; Rodríguez-Sánchez and Arroyo, 2008; Désamoré et al., 2011; Migliore et al., 2012; Besnard et al., 2013; Chen et al., 2014; Hardion et al., 2014). Specific attention has paid to the role of changes in climate as drivers of Mediterranean biodiversity (e.g. Fiz-Palacios and Valcárcel, 2013).

Sound insights into the role of migration were revealed by recent phylogeographical studies done at the family level, examples of which include analyses of Araceae (e.g. Biarum genus, Mansion et al., 2008) and Boraginaceae (Mansion et al., 2009). These phylogenetic analyses of ancestral areas inferred that both westward expansion and vicariance were there prior to diversification, supporting the existence of land corridors along the Tethys shores for flora dispersal from Anatolia, perhaps dating back to the Oligocene. In the case of Boraginaceae, phylogeographical analyses indicate that the Corso-Sardinian islands have been on the receiving end of the North and South Mediterranean migration routes that led to speciation of insular neo-endemics in Anchusa 
Table 1

Taxonomic history of Astragalus sect. Tragacantha DC. according to Bunge (1869), Podlech (2008) and recent botanical literature (Alegro et al., 2009; Bacchetta and Brullo, 2010).

\begin{tabular}{lll}
\hline Bunge 1869 & Podlech 2008 & Current consideration \\
Sect. Melanocercis Bunge & Sect. Tragacantha DC. & Sect. Tragacantha DC. \\
\hline A. angustifolius Lam. & A. dirmilensis Hub.-Mor. \& Reese & A. dirmilensis Hub.-Mor. \& Reese \\
A. angustifolius Lam. & A. renzii Hub.-Mor. \& Reese & A. renzii Hub.-Mor. \& Reese \\
A. angustifolius Lam. & A. angustifolius Lam. & A. angustifolius Lam. \\
A. hermoneus Boiss. & A. angustifolius Lam. & A. angustifolius Lam. \\
A. pungens Willd. & A. angustifolius Lam. & A. angustifolius Lam. \\
A. gymnolobus Fisch. & A. gymnolobus Fisch. & A. gymnolobus Fisch. \\
A. tymphresteus Boiss. \& Spruner & A. tymphresteus Boiss. \& Spruner & A. tymphresteus Boiss. \& Spruner \\
A. sirinicus Ten. & A. sirinicus Ten. & A. sirinicus Ten. \\
A. sirinicus Ten. & A. sirinicus Ten. & A. croaticus Alegro et al. \\
A. sirinicus Ten. & A. genargenteus Moris & A. genargenteus Moris \\
A. sirinicus Ten. & A. gennarii Bacch. \& Brullo & A. gennarii Bacch. \& Brullo \\
A. sirinicus Ten. & A. greuteri Bacch. \& Brullo & A. greuteri Bacch. \& Brullo \\
A. massiliensis Lam. & A. tragacantha L. & A. tragacantha L. \\
A. massiliensis Lam. & A. balearicus Chater & A. balearicus Chater \\
A. massiliensis Lam. & A. thermensis Vals. & A. thermensis Vals. \\
A. massiliensis Lam. & A. terracianoi Vals. & A. terracianoi Vals. \\
A. massiliensis Lam. & A. terracianoi Vals. & A. tegulensis Bacch. \& Brullo \\
- & A. ibrahimianus Maire & A. ibrahimianus Maire \\
\hline
\end{tabular}

(Bacchetta et al., 2008) and Borago (Mansion et al., 2009), respectively. For the xerophytic Haplophylum taxa originating from the semiarid and steppe lands of the Irano-Turanian floristic region, Manafzadeh et al. (2014) hypothesized that westward expansion was driven in the mid-Miocene by the increased aridity arising from the closure of the sea connection between the proto-Mediterranean and the Paratethys. Then, Mediterranean Haplophyllum taxa began to diverge after a Miocene east-west vicariance. Following this, the Iberian endemic taxa began to diversify during the early Pliocene (Navarro et al., 2004; Manafzadeh et al., 2014), a period that could have been favorable to the expansion of xerophytic taxa. Indeed, the short but intense Messinian salinity crisis (5.96-5.33 Mya) resulted in a dramatic drying of the sea, and this facilitated the expansion of xerophytes which colonized the islands by means of emergent land bridges, further shaping land ecosystems (Mansion et al., 2009).

More recently, the onset of glaciations (c. 2.6 Mya, Late Pliocene; Popescu, 2006) favored continent-wide open steppe vegetation with a high diversity of xerophytic plants (Suc, 1984; Suc et al., 1995; Thompson, 2005; Pérez-Collazos et al., 2009). During these interglacial periods, including the present one, it is assumed that the range of steppe plants contracted to refugia, such as those found at particular altitudes (Djamali et al., 2012; Gentili et al., 2015). Among these xerophyte taxa, thorny cushion-like plants from the Fabaceae family have a strong ecological importance among Mediterranean steppe flora. However, their evolutionary history remains poorly understood, and even less in the genus Astragalus which includes hundred of thorny species, and several sections that have convergently evolved to this habit (ZarreMobarakeh, 2000; Hardion et al., 2010). Beyond some molecular phylogenies (Osaloo et al., 2005; Abdel-Samad et al., 2014; Dizkirici et al., 2014), the serious lack of phylogeographic studies limits the understanding of such a diversification in Astragalus and species persistence in the context of global change, despite some analogous works on closely related genera (Phyllolobium, Zhang et al., 2009; Onobrychis, Toluei et al., 2013, Erophaca, Casimiro-Soriguer et al., 2010). We are therefore far from understanding the relative contributions that geographical isolation and ecological differentiation make to persistence and speciation in one of the most species-rich genus of angiosperms (c. 3000 species; Bunge, 1869; Podlech, 2008).

However, an increasing number of morphological studies has led continuous efforts in the description of new endemic Astragalus taxa for a decade (e.g. Mattana et al., 2008; Bacchetta et al., 2011; Brullo et al., 2012; Grillo et al., 2013; Mahmoodi et al., 2013). As an illustration, A. sect. Tragacantha DC. (syn. Melanocercis Bge.) has almost doubling its species richness $(n=16)$ with the description of seven new species within the two last decades (Valsecchi, 1994; Bacchetta and Brullo, 2006, 2010). Distributed in open rocky and sandy habitats in coastal and high-altitude environments, this Mediterranean-wide section has been historically structured into three complexes following ecological, morphological, and geographical criteria (Valsecchi, 1994; Bacchetta and Brullo, 2006 2010; Alegro et al., 2009): (i) the western A. tragacantha complex, which includes only coastal taxa, unlike (ii) the Adriatic $A$. sirinicus complex and (iii) the eastern A. angustifolius complex, which includes only orophyte species (Table 1, Fig. 1). Used historically in the botanical literature (e.g. Nieto-Feliner, 1990), this 'ecomorpho-geo' consensus offers the possibility of labeling well-separated and localized groups of populations for conservation purposes, but it does not clearly elucidate their evolutionary history and diversification. According to a preliminary study (Hardion et al., 2010), the weak molecular divergence among the western taxa of this section could be indicative of a late origin, perhaps as recently as the late Quaternary period. Their current scattered distribution in the western Mediterranean could represent a recent contraction toward open vegetation habitats either along the coastline or in altitude.

Diversification patterns and processes are important issues in recent Mediterranean biogeography literature (e.g. Valente and Vargas, 2013). Within the context of the present research we examine the diversification history of $A$. sect. Tragacantha by testing two main scenarios: based on previous Mediterranean-wide phylogeographies, one can expect the taxonomic diversity of this section has resulted (i) from a diversification after an old vicariance in both east and west sides of the Mediterranean; or alternatively (ii) from a recent western radiation from eastward origin, as previously hypothesized (Hardion et al., 2010). In addition, we test the phylogenetic support for the ecological differentiation structuring this section between coastal and mountain habitats, and its higher taxonomic richness in the Western Mediterranean. We use rDNA ITS sequence data to anchor these analyses to a temporal framework, and Amplified Fragment Length Polymorphism (AFLP) fingerprints to discern closely related taxa on a genome-wide resolution, where ITS find their limits (Hardion et al., 2010). 


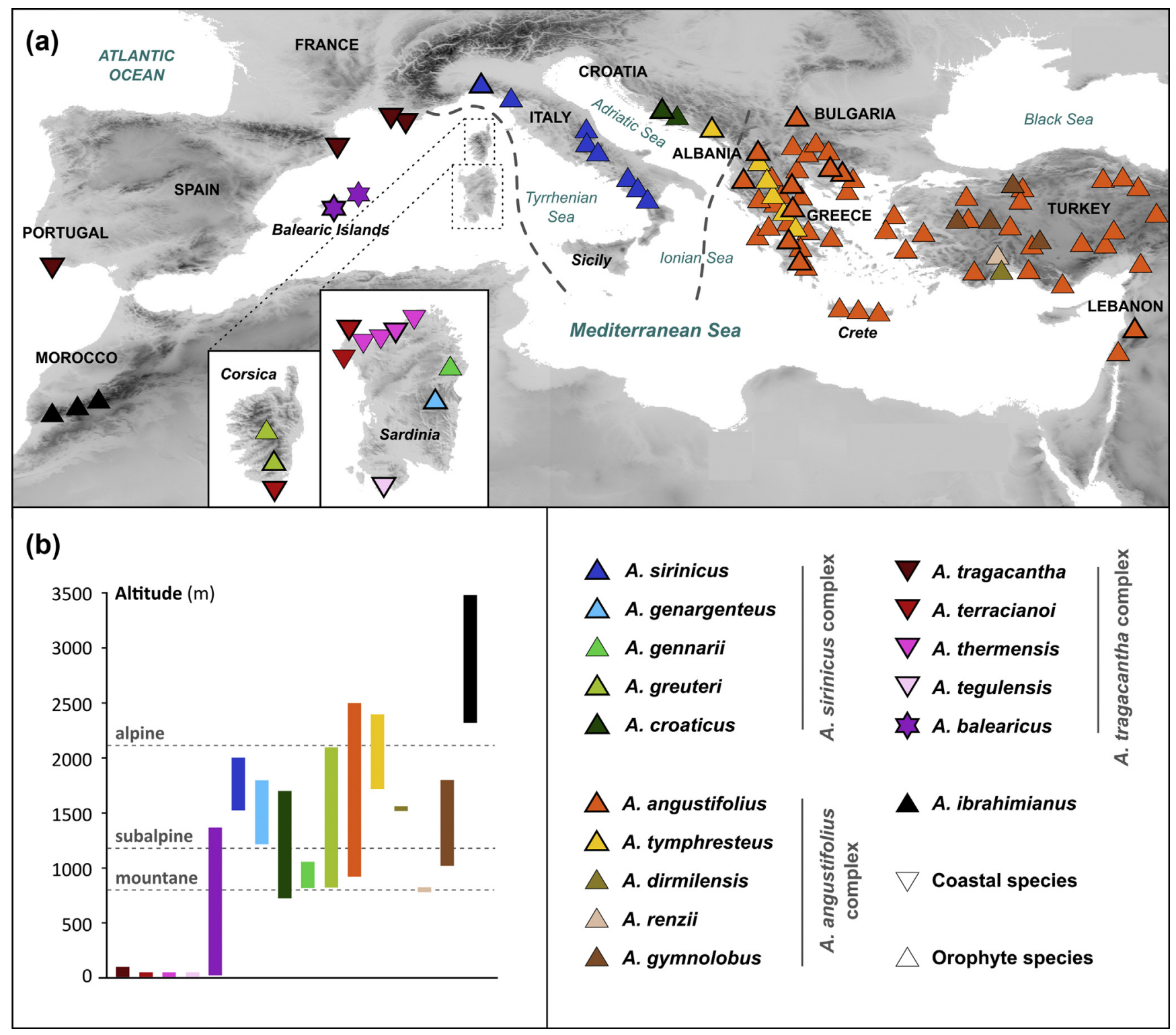

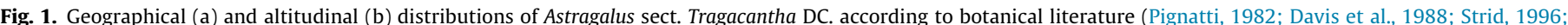

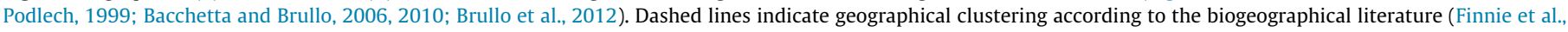

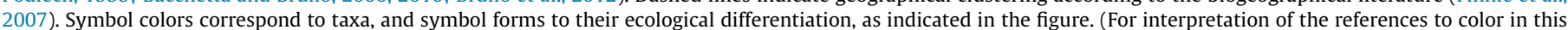
figure legend, the reader is referred to the web version of this article.)

\section{Material and methods}

\subsection{Plant sampling and DNA extractions}

We gathered 75 samples representing 12 of the 16 species currently considered to be part of $A$. sect. Tragacantha. Voucher specimens were deposited in herbaria of the University of Strasbourg (STR, France), the Aix-Marseille University (MARS, France), the University of Cagliari (CAG, Italy) and the Natural History Museum of Rijeka (NHMR, Croatia; details in Table S1, Appendix A). For each sample, leaflets were dried with silica gel and ground up in liquid nitrogen before performing DNA extraction. The DNA extractions followed the CTAB protocol, described by Doyle and Doyle (1987), with some slight modifications (Hardion et al., 2014).

\subsection{Phylogenetic analyses of rDNA ITS sequences}

DNA isolation and rDNA ITS sequencing were performed according to methods described in Abdel-Samad et al. (2014). Our strategy of molecular dating was to include A. sect. Tragacantha taxa in a wider phylogeny of the genus Astragalus, in order to use previously dated nodes in a secondary calibration (Wojciechowski et al., 1999; Wojciechowski, 2005). As it was not realist to include all Genbank data corresponding to Astragalus, the choice of taxa was based on previous works dealing with Astragalus phylogenies (Wojciechowski et al., 1999; Wojciechowski, 2005; Osaloo et al., 2005; Dizkirici et al., 2014). An additional Megablast research attempted to find putative nearest relatives of $A$. sect. Tragacantha in Genbank data. Finally, selected rDNA ITS sequences (Genbank accessions in Table S1, Appendix A) were 
aligned with our sequenced taxa and related taxa to the genus Astragalus used as outgroups for node calibration (i.e. Colutea, Oxytropis, Onobrychis, Erophaca). This custom dataset includes 140 sequences and 114 Astragalus taxa. After alignment (MUSCLE software; Edgar, 2004) the 5.8S and a microsatellite sequence in the ITS 1 were removed. Sequence checking and alignment were done in MEGA v.6 (Tamura et al., 2013). The phylogeny was determined by a Bayesian MCMC analysis using BEAST 1.8 (Drummond et al., 2012). Four independent MCMC analyses were run for a total of 20 millions steps, sampling states every 2000 generations (Cipres Science gateway, Miller et al., 2010). The coalescent theory for molecular data was applied based on the following items: a $\mathrm{K} 2 \mathrm{P}+$ gamma substitution model [which had been selected using the model selection strategies implemented in jModeltest 2 (Darriba et al., 2012)], a Yule process tree prior, a random starting tree and a relaxed log normal clock. Two priors were used for age calibration: the crown node corresponding to the Astragalean clade (normal distribution mean 16.1 Mya, Sd = 1.82) and the crown node of Astragalus (normal distribution mean 12.7 Mya, $\mathrm{Sd}=1.45$ ). These values were chosen according to Wojciechowski (2005). Because rDNA ITS did not support the strict monophyly of $A$. sect. Tragacantha, we generated the same Bayesian analysis with and without prior on its monophyly. For the remaining model parameters, the default programme prior distribution was used. Tracer 1.4 (Rambaut et al., 2014) was used to first check the convergence and mixing of each parameter between runs, and then to estimate the mean and 95\% highest posterior density (HPD) of age nodes, sampled from the posterior distribution of the combined runs. The effective sample size (ESS) of each parameter was sufficient to provide reasonable estimates of the model parameter variances (i.e. ESS values $>200$, after excluding a burn-in fraction of $10 \%$ ). The $x m l$ file containing the alignment and the parameters of BEAST analysis is deposited in Appendix A.

\subsection{AFLP protocol, genetic diversity and relationships}

AFLP protocol was applied according to Hardion et al. (2014) with the following modifications: after a pre-amplification PCR on digested genomes using $\mathrm{Eco}+\mathrm{A}$ and $\mathrm{Mse}+\mathrm{C}$ primers, two selective PCRs were achieved using Eco+AAGG-Mse+CCAG and Eco + AACG-Mse+CAAG primer pairs. These primer pairs were chosen for their efficiency and reliability in a large population genetic study still in progress on A. gummifer, which initially tested two +3 and two +4 primer pairs (Abdel-Samad, 2015). AFLP fingerprints were generated from electrophoretogram alignments using the RawGeno R-package (Arrigo et al., 2009) in R environment ( $R$ Core Team, 2015), following a format conversion using PeakScanner v1.0 (Life Technologies, Waltham, US). Genetic markers were automatically selected among fragments ranging from 50 to 500 bp in length, with a lower signal threshold of 100 relative fluorescent units. Ten replicate samples were randomly chosen, analyzed with other samples, and used in the binary dataset to expunge all non-repeatable markers. Descriptive statistics were estimated using the R-functions described in AFLPdat (Ehrich, 2006). These functions were also used to determine the numbers of private fragments, the percentages of polymorphic fragments and the frequency-down-weighted fragment values calculated as a ratio of means. Then, analysis of molecular variance (AMOVA; Excoffier et al., 1992) was used with the amova R-function from ade4 R-package (Thioulouse et al., 1997) to test the robustness of different clusterings based on geographical, taxonomical, and ecological criteria. To represent phylogenetic relationships based on AFLP data, the NeighborNet algorithm was used to produce a distance-based network using Nei and Li's genetic distances in SplitsTree v.4.13 (Huson and Bryant, 2006).

\section{Results}

\section{1. rDNA ITS phylogeny and molecular dating}

Within $A$. sect. Tragacantha, the rDNA ITS sequence alignment was 420 bp long, with 30 variable nucleotide sites, 25 being parsimony informative. Twenty haplotypes were observed among the 75 individuals sequenced. Their overall mean divergence was $1.0 \%$, ranging from $0.0 \%$ to $2.7 \%$ but this variation supports five clades with good confidence (Bayesian posterior probabilities $>0.95$, named A, B, C and D; Fig. 2).

The analysis was repeated without prior on the monophyly of $A$. sect. Tragacantha: two taxa, $A$. odoratus and A. fragrans, appeared to be nested within the sect. Tragcantha (see Fig. S2, Appendix A). The monophyly of $A$. sect. Tragacantha is questioned by this result but it did not change our inferences about diversification for three reasons. First, even if this prior could be disregarded by Bayesian inferences, they still kept the monophyly of the section in the prior analysis. Second, $A$. odoratus and $A$. fragrans possess highly differentiated morphology from $A$. sect. Tragacantha, and their phylogenetic position is more probably due to homoplasic or paralogous information in rDNA. Third, ages of robust nodes that will be presented below were slightly affected by this point.

The 20 haplotypes were clustered in five clades with good confidence (Bayesian posterior probabilities $>0.95$, named $A, B, C$ and D; Fig. 2). A first clade (node A) unites the haplotypes of the five Corso-Sardinian taxa (Co, Sa) with haplotypes of the continental A. tragacantha (Lu, Fr, Hs), without distinction between coastal and orophyte taxa. Within this clade, the haplotypes are organized according to their geographical origin (node A, Fig. 2; Fig. 1) excepted for one haplotype of $A$. tragacantha sampled in France near Marseille but branched with the Corso-Sardinian clade despite weak support (posterior probability $=0.16$ ). The age of node $\mathrm{A}$ is estimated at 2.7 Mya with a $95 \%$ confidence interval ranging from 1.3 to 4.3 Mya. The clade with roots in node $B$ is composed of haplotypes of $A$. balearicus, A. greuteri, A. croaticus and $A$. tymphresteus, mixing members of the three taxonomic complexes (Table 1). The existence of two divergent rDNA ITS sequences in A. greuteri has therefore been revealed. The age of node $B$ is estimated at 1.9 Mya with a 95\% confidence interval ranging from 0.5 to 3.4 Mya. The third clade (node $C$ ) is only composed of $A$. ibrahimianus linked though a long branch to the clade $B$ and $E$ on an older node estimated to 3.5 Mya but this node is weakly supported (posterior probability $=0.18$ ) and the divergence of $A$. ibrahimianus could be more ancient. The fourth and fifth clades (nodes D and E) are composed of haplotypes of A. angustifolius with a distribution in Balkans and Lebanon, the exception being a single haplotype from Italy belonging to A. sirinicus. Their node ages are estimated to 2.5 and 1.6 Mya respectively.

The crown node age of the section Tragacantha, regarding the former divergence observed in the section, is estimated to be 4.4 Mya with a 95\% CI ranging from 2.5 to 6.4 Mya. Despite the wide confidence interval, the posterior probability distribution of this dating supports a Pliocene origin of $A$. sect. Tragacantha (see posterior distribution; Fig. 2).

\subsection{AFLP clustering and diversities}

The AFLP procedure initially generated 392 polymorphic markers after discarding of non-repeatable markers based on 10 replicate samples. Based on a mean error rate of $2.7 \%$, every plant sample was distinguished as a different genotype, and 365 markers (93.1\%) were parsimony informative.

The NeighborNet (NNet) diagram resulting from this AFLP dataset is well structured, having no strong pattern of reticulation 


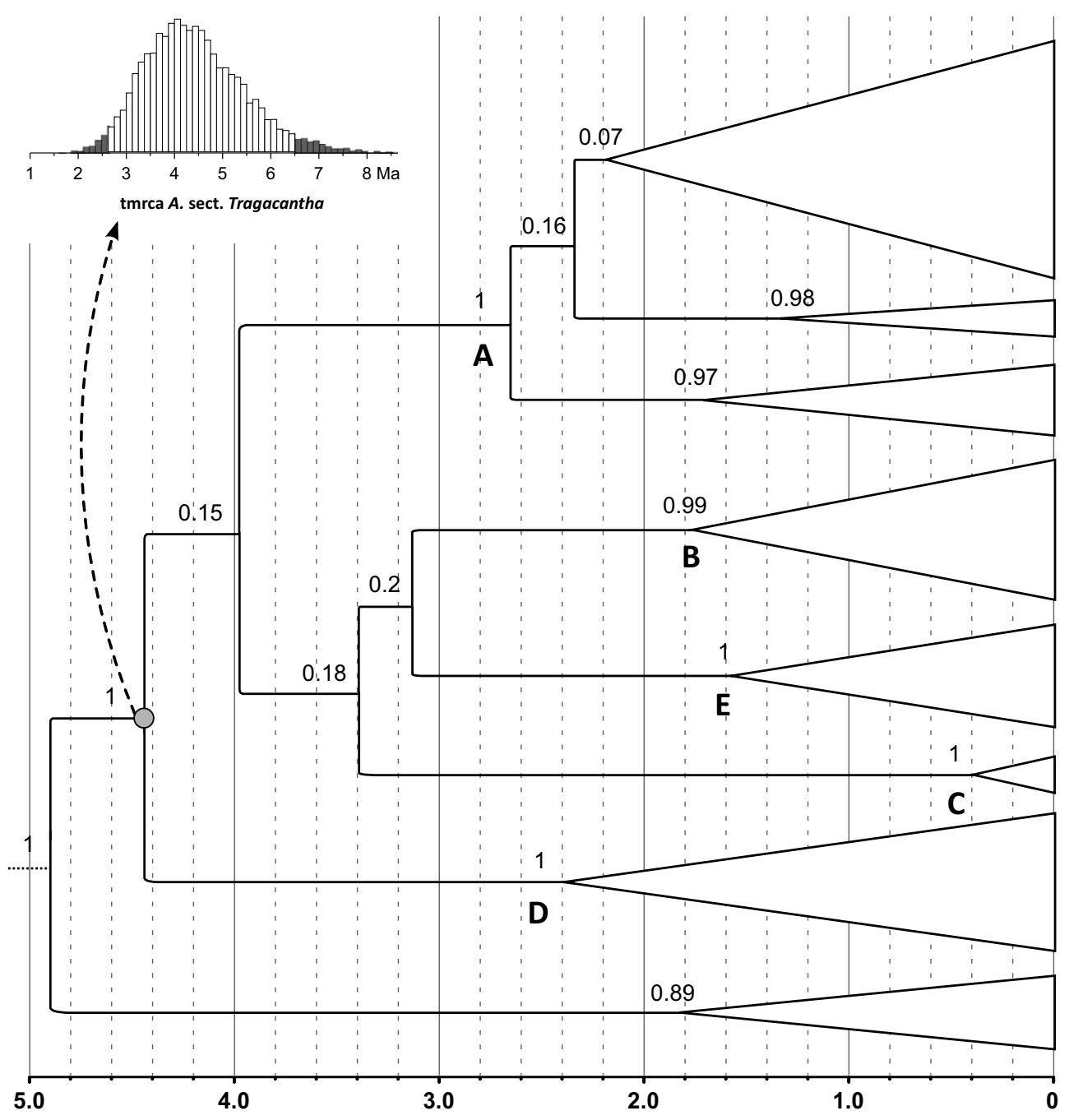

A. genargenteus $\mathrm{Sa}(2)$

A. tegulensis Sa (2) $\nabla$

A. terracianoi Sa (1)

A. terracianoi Co (12)

A. tragacantha $\mathrm{Fr}(2)$

A. thermensis $\mathrm{Sa}(2)$

A. greuteri Co (1)

A. tragacantha Lu (6)

A. tragacantha $\mathrm{Fr}(15)$

A. tragacantha $\mathrm{Hs}(2)$

A. balearicus $\mathrm{BI}(1)$

A. greuteri Co (1)

A. croaticus $\mathrm{Kr}(2) \triangle$

A. tymphresteus Mt (2) $\triangle$

A. angustifolius $\mathrm{Lb}(3)$

A. sirinicus It (3)

A. angustifolius $\mathrm{Gr}(2)$

A. ibrahimianus Mo (2)

A. angustifolius $\mathrm{Gr}(2)$

A. angustifolius $\mathrm{Gr}(10)$

A. angustifolius $\mathrm{Bu}(2)$

A. angustifolius $\mathrm{Al}(2)$

\section{A. fragrans}

A. odoratus

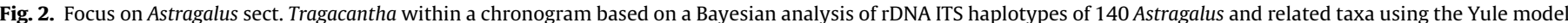

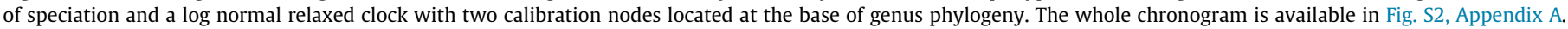

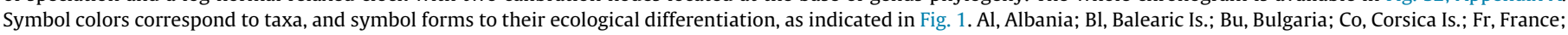

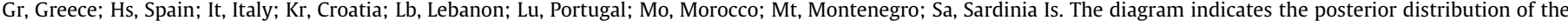

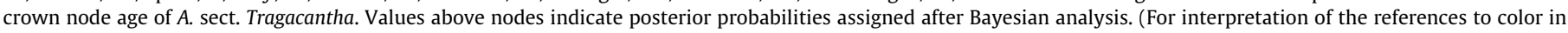
this figure legend, the reader is referred to the web version of this article.)

(Fig. 3). Globally, the clustering follows a longitudinal dimension with western genotypes on the left and eastern genotypes on the right of the NNet (Fig. 3). To the right, the eastern group representing the $A$. angustifolius complex (Table 1) includes a South-Balkan cluster and a Lebanon cluster. The left side of the NNet diagram form a western group that includes the following three main lineages: (i) a cluster containing genotypes of $A$. tragacantha from continental parts of France, Spain, and Portugal; (ii) an insular cluster containing Corso-Sardinian genotypes of $A$. genargenteus, $A$. greuteri, A. thermensis, A. terrancianoi, and A. tegulensis; and (iii) the genotypes of $A$. balearicus, endemic to the Balearic islands. Between the western and eastern clusters, an Adriatic group is represented by Italian and Dalmatian (i.e. NE Balkan) genotypes of $A$. sirinicus, A. croaticus and A. angustifolius. The exception to this geographical structuring is the position of the Moroccan genotypes of A. ibrahimianus, connected in the middle of the NNet between the eastern and central Mediterranean lineages.

To compare genetic diversity among geographic areas (as defined in Fig. 1; dashed lines), A. ibrahimianus genotypes were distinguished due to their high divergence. Genetic diversity measured on AFLPs revealed somewhat higher percentages of polymorphic fragments and greater numbers of private fragments in the eastern $(77.2 \%, 25)$ than in the western part $(70.4 \%, 22$; Table 2), for an equivalent sampling effort ( $n=22$ and 26, respectively), and even though only one species (A. angustifolius) was sampled in the East versus seven taxa to the West. The eastward increase in diversity becomes even clearer when one considers the DW values accounting for marker rarity (Table 2). As observed in the NNnet diagram, A. ibrahimianus has a high genetic originality despite its weak sampling ( $D W=899.5$; Table 2). As a consequence, the pattern of genetic divergence indicated by DW index and private markers supports two main results: (i) a westward decrease in marker rarity, which is contradicted by (ii) the longterm isolation of $A$. ibrahimianus. The AMOVA results reveal that geographical groups have a higher structuring effect on AFLP polymorphism (explaining $24.8 \%$ of genetic variation) than do taxonomic complexes (19.9\%), or even ecological differentiation (17.1\%; Table 3).

The AFLP NNet clusters are congruent with five rDNA ITS clades. This congruence is supported by the overall correlation between AFLP and ITS dissimilarities (Mantel test between matrices of Jaccard distances and \% of nucleotide differences, $r=0.71^{* * *}$, 

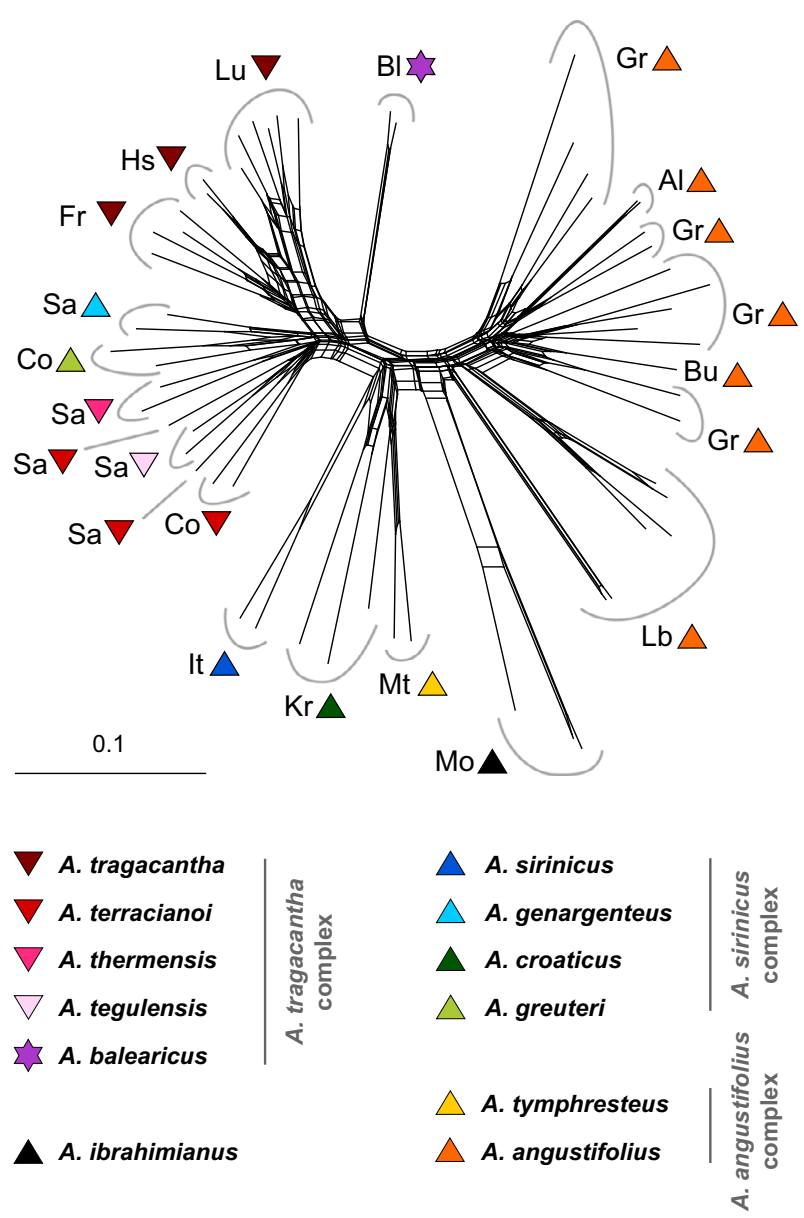

Fig. 3. NeighborNet diagram based on Nei and Li's genetic distances between taxa of Astragalus sect. Tragacantha. Symbol colors correspond to taxa, and symbol forms to their ecological differentiation, as indicated in Fig. 1. Al, Albania; Bl, Balearic Is.; Bu, Bulgaria; Co, Corsica Is.; Fr, France; Gr, Greece; Hs, Spain; It, Italy; Kr, Croatia; Lb, Lebanon; Lu, Portugal; Mo, Morocco; Mt, Montenegro; Sa, Sardinia Is. (For interpretation of the references to color in this figure legend, the reader is referred to the web version of this article.)

Table 2

Genetic diversities of Astragalus sect. Tragacantha among geographical groups (Fig. 1) using Amplified Fragment Length Polymorphism (AFLP).

\begin{tabular}{lrlllll}
\hline & $n$ & sp & $F$ & $\% F$ & PF & DW \\
\hline East & 22 & 1 & 328 & 77.2 & 25 & 674.7 \\
Adriatic & 7 & 3 & 276 & 59.9 & 10 & 636.9 \\
West & 26 & 7 & 309 & 70.4 & 22 & 526.0 \\
Morocco & 3 & 1 & 179 & 20.4 & 6 & 899.5 \\
\hline
\end{tabular}

$n$, number of samples; sp, number of taxa; $F$, number of fragments; PF, number of private fragments; $\%$, percentage of polymorphic fragments; DW, frequencydown-weighted fragment values calculated as a ratio of means.
*** denotes statistical significance level at 0.05 ). Phylogenetic relationships reported by AFLPs or rDNA ITS do not demonstrate a branching pattern of western and Adriatic taxa within eastern lineages, rejecting the scenario of a recent eastern origin for $A$. tragacantha.

\section{Discussion}

Paleoecology and phylogeography literature has poorly addressed the historical biogeography of Mediterranean thorny xerophytes, despite their emblematic place in Mediterranean landscapes (Quézel, 1999). The present study highlights new insights into their evolutionary origin and diversification using thorny taxa of Astragalus sect. Tragacantha. These taxa are distributed among xerothermic zones, in coastal and mountainous habitats throughout the Mediterranean region, making it possible to question the role of geographical isolation and ecological differentiation in speciation processes.

The present study supports an alternative pattern than the previous hypothesis assuming the recent eastward origin of western taxa (Hardion et al., 2010). The history of A. sect. Tragacantha appears to be more complex, indicating a probable Pliocene origin for the entire section. The ITS chronogram rooted $A$. sect. Tragacantha at 4.4. Mya (95\% CI, 2.5-6.4 Mya), and the isolation of the wellsupported western lineage (clade A, Fig. 2) at 2.7 Mya (95\% CI, 1.34.3 Mya), i.e. near the beginning of the Pleistocene. In addition, the AFLP fingerprints revealed a major phylogenetic split between eastern and western lineages. Thus both ITS and AFLP support an ancestral distribution ranging from the Levant to NW Africa and W Europe followed by vicariance events. This evidence is further strengthened by the basal phylogenetic position of the most westerly taxon, the Moroccan A. ibrahimianus. The main phylogeographical split revealed here is in accordance with the bipolar structures also revealed by other Mediterranean-wide phylogeographies, e.g. for Myrtus communis (Migliore et al., 2012), Laurus (Rodríguez-Sánchez et al., 2009), Haplophyllum (Manafzadeh et al., 2014), Smilax aspera (Chen et al., 2014), and several other cases (Kadereit and Yaprak, 2008). According to our results, the timing of this vicariance within Astragalus sect. Tragacantha dates to the early Pliocene (i.e. near 5 Mya) and the five main lineages detected in the rDNA phylogeny already existed at the late Pliocene or early Pleistocene at 2 Mya.

Another important feature of our study concerns the geographical isolation as the main driver of genetic differentiation. Indeed AFLPs lineages correspond to geographical units and this pattern is observed not only at a coarse scale (i.e. west-central-east structuring) but also at finer scales, as for the divergence between Corso-Sardinian taxa and west continental ones (Portugal, Spain, France), or between Balkan and Near East (Lebanon) populations of $A$. angustifolius (Fig. 3). In agreement with an increasing number of phylogeographies our results add support to the role of migration-isolation cycles during the evolutionary history of Mediterranean plant species (Pineiro et al., 2007; Mansion et al., 2009; Guzmán and Vargas, 2010; Migliore et al., 2012; Garnatje

Table 3

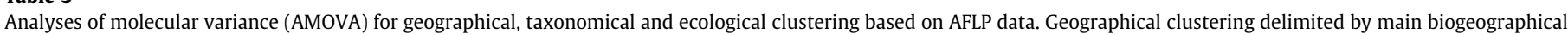

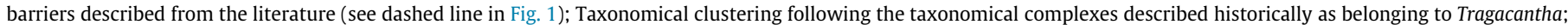
Ecological clustering according to the orophyte or coastal ecological traits (Fig. 1).

\begin{tabular}{|c|c|c|c|c|c|c|c|c|c|}
\hline \multirow[t]{2}{*}{ Source of variation } & \multicolumn{3}{|c|}{ Geographical clustering } & \multicolumn{3}{|c|}{ Taxonomical clustering } & \multicolumn{3}{|c|}{ Ecological clustering } \\
\hline & $\mathrm{df}$ & Sum of squares & $\%$ of variation & $\mathrm{df}$ & Sum of squares & $\%$ of variation & df & Sum of squares & $\%$ of variation \\
\hline Among groups & 2 & 2.00 & 24.8 & 2 & 1.73 & 19.9 & 1 & 1.09 & 17.1 \\
\hline Among samples & 22 & 4.87 & 34.7 & 22 & 5.14 & 38.6 & 23 & 5.78 & 42.1 \\
\hline Within samples & 27 & 2.16 & 40.5 & 27 & 2.16 & 41.5 & 27 & 2.16 & 40.8 \\
\hline
\end{tabular}


et al., 2013; De Castro et al., 2015). The land connections established during the Messinian salt crisis ending 5.3 Mya ago could have eased long distance migration of xerophytes taxa such as Astragalus thorny cushion plants. However the main lineages began to diversify after this period near the limit between the Pliocene and the Pleistocene (1.8-2.6 Mya; see crown node ages A, B, C, D and E, Fig. 2), a period which is the scene of the first Mediterranean climatic fluctuations with steppe-forest alternations that will characterized the Pleistocene (Suc et al., 1995; Jiménez-Moreno et al., 2010). This period coming flanked by the Messinian salt crisis and the beginning of quaternary glaciations was the scene of intense speciation in several families of Mediterranean flora (see Gaudeul et al., 2016). The analysis of diversification rate done by Fiz-Palacios and Valcárcel (2013) on 36 Mediterranean plant lineages revealed a post-Messinian gap in cladogenesis, and that for $39 \%$ of them a recovery of diversification with the Mediterranean climate onset. According to our results, it seems effectively that a gap between old and recent diversification occurred within the sect. Tragacantha, as it can be seen in both AFLP and ITS phylogenetic distances. However, the recovery appeared to be slightly more recent than the Mediterranean climate onset (3.4 Mya; Jiménez-Moreno et al., 2010). New data based on additional DNA sequences will certainly help to narrow confidence intervals for a better evaluation of respective role of the Mediterranean climate onset versus the Pleistocene climatic oscillations in the cladogenesis of these Mediterranean thorny cushion plants. However, standardly used cpDNA sequences as matK gene, trnL-trnF spacer or $n d h F$ gene failed to supply additional support in our analyses due to their strong uniformity (data not shown).

Finally, our results bear new insights on the ecogeographical isolation criterion. The taxonomy of $A$. sect. Tragacantha was historically based on three main species, the western coastal $A$. tragacantha, the Italo-Balkan orophyte $A$. sirinicus and the eastern orophyte A. angustifolius (Valsecchi, 1994; Bacchetta and Brullo, $2006,2010)$. The different taxa described from or put in synonym of these three species were then grouped in three complexes. Even as a legacy of taxonomic history, these complexes are defined by an ecogeographical consistency (Bacchetta and Brullo, 2006, 2010; Brullo et al., 2012). Consequently, one can expect a phylogenetic support for the differentiation between coastal and mountainous habitats. With the stark contrast between the characteristics of these environments, it is reasonable to assume that local adaptation and ecological reproductive isolation lead to a significant genetic differentiation between coastal and mountainous populations (Lowry et al., 2008). However, Corso-Sardinian coastal taxa appear to be genetically more related to Corso-Sardinian mountain species than to continental coastal taxa on the NNet diagram (Fig. 3). These results question the isolation of coastal and mountain taxa of the Corso-Sardinian islands, but also the current taxonomy of the section in different eco-geographical complexes ( $A$. angustifolius, $A$. sirinicus and A. tragacantha complexes; Fig. 1) for which altitude is a crucial criterion. According to molecular data, the geographical isolation is a better hypothesis for the main structuring force of genetic differentiation in A. sect. Tragacantha. Similar patterns were previously evidenced by the Heliosperma pusillum group (Caryophyllaceae), where the ecological distinction between low vs. high elevation taxa was initially chosen as the main taxonomical criterion, but was later refuted by molecular markers (Flatscher et al., 2012). These authors rather hypothesized a putative ecological distinction of ecotypes based on heritable epigenetic variation. Concerning Corso-Sardinian taxa, the lack of molecular divergence revealed here between taxa inhabiting different ecological conditions is not congruent with the phylogenetic differentiation of Sardinian Anchusa endemic species between coastal and mountainous habitats (Bacchetta et al., 2008). The phylogenetic divergence between Corso-Sardinian taxa is even lower than between the three continental populations of $A$. tragcantha (between France, Spain and Portugal). This weak genetic divergence could be due to the recent foundation of these taxa in separate part of the islands from a common ancestor (Fig. 1) or to repeated genetic admixture due to altitude convergence during favorable climatic periods, i.e. Pleistocene glaciations. Glacial induced altitudinal migrations were also invoked to explain genetic similarity between different taxa of Armeria (Plumbaginaceeae) which are currently isolated in coastal and mountain habitats as A. sect. Tragacantha (Gutiérrez Larena et al., 2002). Consequently, the reproductive isolation of the Corso-Sardinian taxa remains an open question and their taxonomic status (species or ecotypes) is awaiting further analyses with evolutionary approaches. In addition, only an integrative study integrating molecular markers to morphological characters on a broad sampling will allow a reliable taxonomical revision of $A$. sect. Tragacantha.

\section{Conclusions}

Our comprehensive results on $A$. sect. Tragacantha underscore the promise of new studies relating range expansion and fragmentation for plant diversification in the Mediterranean region. If Mediterranean refugia have accumulated diversity (Nieto-Feliner, 2014), it could be also interesting to analyze how range fragmentation triggered by climate change could have generated diversity. In 1997, Chown questioned rarity and reduced abundance as potential factors to stimulate diversification. Along these lines, the western Mediterranean xerophytes confined to stressful habitats represent overlooked case studies that could further an understanding of how biodiversity persists through climate change (Hampe and Jump, 2011; Moritz and Agudo, 2013).

\section{Acknowledgments}

The authors thank Cyril Chatelain (Conservatoire et Jardin Botaniques de la Ville de Genève) and Manuel Joao Pinto (Botanical Garden of the Natural History Museum of Lisbon University) for plant sampling, and Nathalie Duong (IMBE), Marianick Juin (IMBE), and Anne Roig (INRA) for their help in applying the AFLP protocol. B.S. thanks Dmitar Lakušić and Nevena Kuzmanović (both Belgrade, Serbia), and Zoran Nikolov (Skopje, Macedonia) for their valuable help in the field and for plant collections. The English language was edited and improved by the professional service of Kolo Wamba (Proediting, San Diego, CA).

\section{Appendix A. Supplementary material}

Supplementary data associated with this article can be found, in the online version, at http://dx.doi.org/10.1016/j.ympev.2016.01. 006.

\section{References}

Abdel-Samad, F., Baumel, A., Juin, M., Pavon, D., Siljak-Yakovlev, S., Médail, F., Kharrat, M.B.D., 2014. Phylogenetic diversity and genome sizes of Astragalus (Fabaceae) in the Lebanon biogeographical crossroad. Plant Syst. Evol. 300, 819830.

Abdel-Samad, F., 2015. Caractérisation écogéographique et génétique du genre Astragalus du Liban: approches de conservation biogéographique. $\mathrm{PhD}$ thesis. Aix-Marseille University, 210pp.

Alegro, A., Bogdanović, S., Brullo, S., del Galdo, G.G., 2009. Astragalus croaticus (Fabaceae), a new species from Croatia. Ann. Bot. Fenn. 46, 569-573.

Arrigo, N., Tuszynski, J.W., Ehrich, D., Gerdes, T., Alvarez, N., 2009. Evaluating the impact of scoring parameters on the structure of intra-specific genetic variation using RawGeno, an R package for automating AFLP scoring. BMC Bioinformatics $10,33$.

Bacchetta, G., Brullo, S., 2006. Taxonomic revision of the Astragalus genargenteus complex (Fabaceae). Willdenowia 36, 157-167. 
Bacchetta, G., Brullo, S., 2010. Astragalus tegulensis Bacch. \& Brullo (Fabaceae), a new species from Sardinia. Candollea 65, 5-14.

Bacchetta, G., Coppi, A., Pontecorvo, C., Selvi, F., 2008. Systematics, phylogenetic relationships and conservation of the taxa of Anchusa (Boraginaceae) endemic to Sardinia (Italy). Syst. Biodivers. 6, 161-174.

Bacchetta, G., Fenu, G., Grillo, O., Mattana, E., Venora, G., 2011. Identification of Sardinian species of Astragalus section Melanocercis (Fabaceae) by seed image analysis. Ann. Bot. Fenn. 48, 449-454.

Besnard, G., El Bakkali, A., Haouane, H., Baali-Cherif, D., Moukhli, A., Khadari, B. 2013. Population genetics of Mediterranean and Saharan olives: geographic patterns of differentiation and evidence for early generations of admixture. Ann. Bot. 112, 1293-1302.

Brullo, S., del Galdo, G.G., Musarella, C.M., 2012. Taxonomic revision of Astragalus angustifolius group (Fabaceae). Bocconea 24, 19-52.

Bunge, A., 1869. Generis Astragali species Gerontogeae. Pars altera, Speciarum enumeratio. Mém Acad. Imp. Sci. St. Petersbourg ser. VII 15, 1-245.

Casimiro-Soriguer, R., Talavera, M., Balao, F., Terrab, A., Herrera, J., Talavera, S., 2010. Phylogeny and genetic structure of Erophaca (Leguminosae), a East-West Mediterranean disjunct genus from the Tertiary. Mol. Phylogenet. Evol. 56, 441450.

Chen, C., Qi, Z.C., Xu, X.H., Comes, H.P., Koch, M.A., Jin, X.J., Qiu, Y.X., 2014. Understanding the formation of Mediterranean-African-Asian disjunctions: evidence for Miocene climate-driven vicariance and recent long-distance dispersal in the Tertiary relict Smilax aspera (Smilacaceae). New Phytol. 204, $243-255$.

Chown, S.L., 1997. Speciation and rarity: separating cause from consequence. In: Kunin, W.E., Gaston, K.J. (Eds.), The Biology of Rarity. Chapman and Hall, London, pp. 91-107.

Darriba, D., Taboada, G.L., Doallo, R., Posada, D., 2012. JModelTest 2: more models, new heuristics and parallel computing. Nat. Methods 9, 772.

Davis, P.H., Mill, R.R., Tan, K., 1988. Flora of Turkey and the East Aegean Islands, vol. 10. Edinburgh University Press.

De Castro, O., Véla, E., Vendramin, G.G., Gargiulo, R., Caputo, P., 2015. Genetic structure in the Genista ephedroides complex (Fabaceae) and implications for its present distribution. Bot. J. Linn. Soc. 177, 607-618.

Désamoré, A., Laenen, B., Devos, N., Popp, M., González-Mancebo, J.M., Carine, M.A. Vanderpoorten, A., 2011. Out of Africa: North-westwards Pleistocene expansions of the heather Erica arborea. J. Biogeogr. 38, 164-176.

Doyle, J., Doyle, J.L., 1987. Genomic plant DNA preparation from fresh tissue-CTAB method. Phytochem. Bull. 19, 11-15.

Dizkirici, A., Ekici, M., Kaya, Z., 2014. Comparative molecular phylogenetics of Astragalus L. sections from Turkey with New World Astragalus species using nrDNA ITS sequences. Plant Syst. Evol. 300, 163-175.

Djamali, M., Baumel, A., Brewer, S., Jackson, S.T., Kadereit, J.W., Lopez-Vinyallonga, S., Mehregan, I., Shabanian, E., Simakova, A., 2012. Ecological implications of Cousinia Cass. (Asteraceae) persistence through the last two glacial-interglacial cycles in the continental Middle East for the Irano-Turanian flora. Rev. Palaeobot. Palyno. 172, 10-20.

Drummond, A.J., Suchard, M.A., Xie, D., Rambaut, A., 2012. Bayesian phylogenetics with BEAUti and the BEAST 1.7. Mol. Biol. Evol. 29, 1969-1973.

Edgar, R.C., 2004. MUSCLE: multiple sequence alignment with high accuracy and high throughput. Nucleic Acids Res. 32, 1792-1797.

Ehrich, D., 2006. AFLPdat: a collection of $\mathrm{R}$ functions for convenient handling of AFLP data. Mol. Ecol. Notes 6, 603-604.

Excoffier, L., Smouse, P.E., Quattro, J.M., 1992. Analysis of molecular variance inferred from metric distances among DNA haplotypes: application to human mitochondrial DNA restriction data. Genetics 131, 479-491.

Finnie, T.J., Preston, C.D., Hill, M.O., Uotila, P., Crawley, M.J., 2007. Floristic elements in European vascular plants: an analysis based on Atlas Florae Europaeae. J. Biogeogr. 34, 1848-1872.

Fiz-Palacios, O., Valcárcel, V., 2013. From Messinian crisis to Mediterranean climate: a temporal gap of diversification recovered from multiple plant phylogenies. Perspect. Plant Ecol. 15, 130-137.

Flatscher, R., Frajman, B., Schönswetter, P., Paun, O., 2012. Environmental heterogeneity and phenotypic divergence: can heritable epigenetic variation aid speciation? Gen. Res. Int. 2012, 9. http://dx.doi.org/10.1155/2012/698421.

Gaudeul, M., Véla, E., Rouhan, G., 2016. Eastward colonization of the Mediterranean Basin by two geographically structured clades: the case of Odontites Ludw. (Orobanchaceae). Mol. Phyl. Evol. 96, 140-149. http://dx.doi.org/10.1016/j. ympev.2015.12.008.

Garnatje, T., Pérez Collazos, E., Pellicer, J., Catalán, P., 2013. Balearic insular isolation and large continental spread framed the phylogeography of the western Mediterranean Cheirolophus intybaceus s.l. (Asteraceae). Plant Biol. 15, 166-175.

Gentili, R., Bacchetta, G., Fenu, G., Cogoni, D., Abeli, T., Rossi, G., Salvatore, M.C., Baroni, C., Citterio, S., 2015. From cold to warm-stage refugia for boreo-alpine plants in southern European and Mediterranean mountains: the last chance to survive or an opportunity for speciation? Biodiversity 16, 247-261.

Grillo, O., Mattana, E., Fenu, G., Venora, G., Bacchetta, G., 2013. Geographic isolation affects inter-and intra-specific seed variability in the Astragalus tragacantha complex, as assessed by morpho-colorimetric analysis. C.R. Biol. 336, 102-108.

Gutiérrez Larena, B., Fuertes Aguilar, J., Nieto Feliner, G., 2002. Glacial-induced altitudinal migrations in Armeria (Plumbaginaceae) inferred from patterns of chloroplast DNA haplotype sharing. Mol. Ecol. 11, 1965-1974.

Guzmán, B., Vargas, P., 2010. Unexpected synchronous differentiation in Mediterranean and Canarian Cistus (Cistaceae). Perspect. Plant Ecol. 12, 163174.
Hampe, A., Jump, A.S., 2011. Climate relicts: past, present, future. Ann. Rev. Ecol. Evol. Syst. 42, 313-333.

Hardion, L., Baumel, A., Dumas, P.J., Duong, N., Affre, L., Tatoni, T., 2010. Phylogenetic relationships and infrageneric classification of Astragalus tragacantha $\mathrm{L}$. (Fabaceae), inferred from nuclear ribosomal DNA Internal transcribed spacers data (nrDNA ITS). Ecologia Mediterranea 36, 99-106.

Hardion, L., Baumel, A., Verlaque, R., Vila, B., 2014. Distinct evolutionary histories of lowland biota on Italian and Balkan peninsulas revealed by the phylogeography of Arundo plinii (Poaceae). J. Biogeogr. 41, 2150-2161.

Huson, D.H., Bryant, D., 2006. Application of phylogenetic networks in evolutionary studies. Mol. Biol. Evol. 23, 254-267.

Jiménez-Moreno, G., Fauquette, S., Suc, J.P., 2010. Miocene to Pliocene vegetation reconstruction and climate estimates in the Iberian Peninsula from pollen data. Rev. Palaeobot. Pal. 162, 403-415.

Kadereit, G., Yaprak, A.E., 2008. Microcnemum coralloides (ChenopodiaceaeSalicornioideae): an example of intraspecific East-West disjunctions in the Mediterranean region. Anales Jard. Bot. Madrid 65, 415-426.

Lowry, D.B., Rockwood, R.C., Willis, J.H., 2008. Ecological reproductive isolation of coast and inland races of Mimulus guttatus. Evolution 62, 2196-2214.

Mahmoodi, M., Maassoumi, A.A., Noroozi, J., 2013. A new alpine species and a new record of Astragalus sect. Stereothrix (Fabaceae) from Iran, with comments on the phytogeography of the section. Willdenowia 43, 263-270.

Manafzadeh, S., Salvo, G., Conti, E., 2014. A tale of migrations from east to west: the Irano-Turanian floristic region as a source of Mediterranean xerophytes. J Biogeogr. 41, 366-379.

Mansion, G., Rosenbaum, G., Schoenenberger, N., Bacchetta, G., Rosselló, J.A., Conti, E., 2008. Phylogenetic analysis informed by geological history supports multiple, sequential invasions of the Mediterranean Basin by the angiosperm family Araceae. Syst. Biol. 57, 269-285.

Mansion, G., Selvi, F., Guggisberg, A., Conti, E., 2009. Origin of Mediterranean insula endemics in the Boraginales: integrative evidence from molecular dating and ancestral area reconstruction. J. Biogeogr. 36, 1282-1296.

Mattana, E., Grillo, O., Venora, G., Bacchetta, G., 2008. Germplasm image analysis of Astragalus maritimus and A. verrucosus (subgen. Trimeniaeus). Anales Jard. Bot. Madrid 65, 149-155.

Miller, M.A., Pfeiffer, W., Schwartz, T., 2010. Creating the CIPRES Science Gateway for inference of large phylogenetic trees. In: Proceedings of the Gateway Computing Environments Workshop, New Orleans, pp. 1-8.

Moritz, C., Agudo, R., 2013. The future of species under climate change: resilience or decline? Science 341, 504-508.

Migliore, J., Baumel, A., Juin, M., Médail, F., 2012. From Mediterranean shores to central Saharan mountains: key phylogeographical insights from the genus Myrtus. J. Biogeogr. 39, 942-956.

Navarro, F.B., Suarez-Santiago, V.N., Blanca, G., 2004. A new species of Haplophyllum A. Juss. (Rutaceae) from the Iberian Peninsula: evidence from morphological karyological and molecular analyses. Ann. Bot. 94, 571-582.

Nieto-Feliner, G., 1990. Armeria. In: Castroviejo, S., Laínz, M., López González, G. Montserrat, P., Muñoz Garmendia, F., Paiva, J., Villar, L. (Eds.), Flora Iberica. Plantas vasculares de la Peninsula Iberica e Islas Baleares. Vol. II. PlatanaceaePlumbaginaceae. Real Jardin Botanico, Madrid, pp. 642-721.

Nieto Feliner, G., 2014. Patterns and processes in plant phylogeography in the Mediterranean Basin. A review. Perspect. Plant Ecol. Evol. Syst. 16, 265-278.

Osaloo, K.S., Maassoumi, A.A., Murakami, N., 2005. Molecular systematics of the Old World Astragalus (Fabaceae) as inferred from nrDNA ITS sequence data. Brittonia 57, 367-381.

Pignatti, S., 1982. Flora d'Italia. 3 vols. Edagricole, Bologna.

Pérez-Collazos, E., Sanchez-Gómez, P., Jiménez, J.F., Catalán, P., 2009. The phylogeographical history of the Iberian steppe plant Ferula loscosi (Apiaceae): a test of the abundant-centre hypothesis. Mol. Ecol. 18, 848-861.

Pineiro, R., Aguilar, J.F., Munt, D.D., Feliner, G.N., 2007. Ecology matters: AtlanticMediterranean disjunction in the sand-dune shrub Armeria pungens (Plumbaginaceae). Mol. Ecol. 16, 2155-2171.

Podlech, D., 1999. Astragalus L. In: Talavera, S., Aedo, C., Castroviejo, S., Romero Zarco, C., Sáez, L., Salgueiro, F.J., Velayos, M. (Eds.), Flora Iberica 7, pp. 279-338 Servicio de Publicaciones del CSIC, Madrid.

Podlech, D., 2008. Thesaurus Astragalorum: Index of all taxa described within the genus Astragalus L. and other genera but belonging to the genus Astragalus: taxa of the Old World and related taxa of the New World. München <http://www. sysbot.biologie.uni-muenchen.de/de/personen/podlech/thesaurus_astragalus. pdf>.

Popescu, S.M., 2006. Late Miocene and early Pliocene environments in the southwestern Black Sea region from high-resolution palynology of DSDP Site 380A (Leg 42B). Palaeogeogr. Palaeocl. 238, 64-77.

Quézel, P., 1999. Les grandes structures de végétation en région méditerranéenne: facteurs déterminants dans leur mise en place post-glaciaire. Geobios 32, 19 32.

Rambaut, A., Suchard, M.A., Xie, D., Drummond, A.J., 2014. Tracer v1.6, available from <http://beast.bio.ed.ac.uk/Tracer>.

R Core Team, 2015. R: A language and environment for statistical computing. $\mathrm{R}$ foundation for statistical computing, Vienna, Austria. ISBN 3-900051-07-0 <http://www.R-project.org>.

Rodríguez-Sánchez, F., Arroyo, J., 2008. Reconstructing the demise of Tethyan plants: climate-driven range dynamics of Laurus since the Pliocene. Global Ecol. Biogeogr. 17, 685-695.

Rodríguez-Sánchez, F., Guzmán, B., Valido, A., Vargas, P., Arroyo, J., 2009. Late Neogene history of the laurel tree (Laurus L., Lauraceae) based on 
phylogeographical analyses of Mediterranean and Macaronesian populations. J. Biogeogr. 36, 1270-1281.

Strid, A., 1996. Phytogeographia Aegaea and the flora Hellenica database. Ann. Naturhist. Mus. Wien 98 (B Suppl.), 279-289.

Suc, J.P., 1984. Origin and evolution of the Mediterranean vegetation and climate in Europe. Nature 307, 429-432.

Suc, J.P., Bertini, A., Combourieu-Nebout, N., Diniz, F., Leroy, S., Russo-Ermolli, E. Zheng, Z., Bessais, E., Ferrier, J., 1995. Structure of West Mediterranean vegetation and climate since $5.3 \mathrm{Ma}$. Acta Zoological Cracoviense 38, 3-16.

Tamura, K., Stecher, G., Peterson, D., Filipski, A., Kumar, S., 2013. MEGA6: molecular evolutionary genetics analysis version 6.0. Mol. Biol. Evol. 30, 2725-2729.

Thioulouse, J., Chessel, D., Dole, S., Olivier, J.M., 1997. ADE-4: a multivariate analysis and graphical display software. Stat. Comput. 7, 75-83.

Thompson, J.D., 2005. Plant Evolution in the Mediterranean. Oxford University Press, Oxford.

Toluei, Z., Atri, M., Ranjbar, M., Wink, M., 2013. Iranian Onobrychis carduchorum (Fabaceae) populations: morphology, ecology and phylogeography. Plant Ecol. Evol. 146, 53-67.
Valente, L.M., Vargas, P., 2013. Contrasting evolutionary hypotheses between two Mediterranean climate floristic hotspots: the Cape of southern Africa and the Mediterranean Basin. J. Biogeogr. 40, 2032-2046.

Valsecchi, F., 1994. Sul complesso Astragalus tragacantha L. (Leguminosae) nel Mediterraneo. Webbia 49, 31-41.

Wojciechowski, M.F., Sanderson, M.J., Hu, J.M., 1999. Evidence on the monophyly of Astragalus (Fabaceae) and its major subgroups based on nuclear ribosomal DNA ITS and chloroplast DNA trnL intron data. Syst. Bot. 24, 409-437.

Wojciechowski, M.F., 2005. Astragalus (Fabaceae): a molecular phylogenetic perspective. Brittonia 57, 382-396.

Zarre-Mobarakeh, S., 2000. Systematic revision of Astragalus sect. Adiaspastus, sect. Macrophyllium and sect. Pterophorus (Fabaceae). Englera, 3-219.

Zhang, M., Kang, Y., Zhou, L., Podlech, D., 2009. Phylogenetic origin of Phyllolobium with a further implication for diversification of Astragalus in China. J. Integr. Plant Biol. 51, 889-899. 